\title{
The challenge of middle-income countries to development assistance for health: recipients, funders, both or neither?
}

\author{
TRYGVE OTTERSEN* \\ Oslo Group on Global Health Policy, Department of Community Medicine and Global Health and Centre for Global \\ Health, University of Oslo, Oslo, Norway \\ Department of Global Public Health and Primary Care, University of Bergen, Bergen, Norway \\ Department of International Public Health, Norwegian Institute of Public Health, Oslo, Norway \\ SUERIE MOON \\ Harvard T.H. Chan School of Public Health, Harvard University, Boston, MA, USA \\ JOHN-ARNE RØTTINGEN \\ Harvard T.H. Chan School of Public Health, Harvard University, Boston, MA, USA \\ Department of Health Management and Health Economics, University of Oslo, Oslo, Norway \\ Infectious Disease Control and Environmental Health, Norwegian Institute of Public Health, Oslo, Norway
}

\begin{abstract}
Recent developments have transformed the role and characteristics of middle-income countries (MICs). Many stakeholders now question the appropriate role of MICs in the system of development assistance for health (DAH), and key funders have already recast their approach to these countries. The pressing question is whether MICs should be recipients, funders, both or neither. The answer has deep implications for individual countries and their citizens, and for the DAH system as a whole. We clarify the fundamental issues involved and emphasise a special feature of many MICs: mid-level gross national income per capita (GNIpc) combined with substantial health needs and large inequalities. We discuss the trade-off between concerns for capacity and need, and illustrate a capacity-based approach to setting the level of a GNIpc eligibility threshold. We also discuss how needs-based exceptions and incentive-preserving instruments can complement such a threshold. Against this background, we outline options for the future roles of MICs in various circumstances. We conclude that major players in the DAH system have reason to reconsider the criteria for allocating DAH among countries and the norms for which countries should contribute and how much.
\end{abstract}

\footnotetext{
*Correspondence to: Trygve Ottersen, Department of Community Medicine and Global Health, Institute of Health and Society, PO Box 1130 Blindern, 0318 Oslo, Norway. Email: trygve.ottersen@ medisin.uio.no
} 


\section{Introduction}

\section{Recent changes}

Recent developments have transformed the role and characteristics of middleincome countries (MICs), as defined by the World Bank. The MICs have increased in number, and the economies of many of current MICs have been rapidly growing, yet often coupled with rising or persistent within-country inequalities. The MIC category now comprises 105 countries (fiscal year 2015), 70\% of the world's population, over $30 \%$ of the global GDP, over $75 \%$ of the world's poor, and almost $70 \%$ of the disease burden in the world (Sumner, 2012) [based on data from the World Bank and the Institute for Health Metrics and Evaluation (IHME)].

These transitions have reinforced a special feature of MICs collectively and of many MICs individually: mid-level gross national income per capita (GNIpc) combined with substantial poverty and unmet health needs and large inequalities in income and health. For example, in several of these countries, the under-five mortality rate (U5MR) in the lowest wealth quintile is more than double the rate in the highest wealth quintile [World Health Organisation (WHO), 2015]. Moreover, many MICs are now both recipients and increasingly significant funders of aid [Global Health Strategies initiatives (GHSi), 2012; IHME, 2016].

\section{Challenge and key questions}

In response to these changes, many have questioned the role of MICs in the system of development assistance for health (DAH). The pressing question is this: should MICs be DAH recipients, funders, both, or neither? As nearly all countries are DAH funders to some extent, for example through their contributions to the UN system, the real question is about which countries should be significant recipients and funders. This is currently a topic of intense debate, and the positions differ widely, as expressed in both word and action. On the one side are those who support that aid should be concentrated in low-income countries (LICs), and in line with this view, Gavi, the Vaccine Alliance (Gavi) and the International Development Association (IDA) use eligibility thresholds that exclude most and nearly all MICs, respectively. On the other side are those who support that most or all MICs should be fully eligible for development assistance or at least provide forceful arguments to that end (Glennie, 2011; Verbeke and Renard, 2011; Kanbur and Sumner, 2012; Glassman et al., 2013). Corresponding to this, funders such as the Global Fund to Fight AIDS, Tuberculosis and Malaria (Global Fund), the United Nations Children's Fund (UNICEF) and the United Nations Development Programme (UNDP) consider all MICs eligible for assistance (reference to paper by Ottersen, Kamath, Moon, Martinsen and Røttingen in this series).

Despite this profound divergence in approaches to MICs, there have been relatively few comprehensive analyses of the various roles they may play in 
development assistance (Glennie, 2011; Verbeke and Renard, 2011; Kanbur and Sumner, 2012; Alonso et al., 2014; Kanbur, 2016), and hardly any such inquiries with regard to DAH (Glassman et al., 2013).

Underlying the specific question about MICs is also a fundamental question for the DAH system: what should be the criteria for identifying recipient and funding countries? Linked to both questions is the issue of country classification and income classification in particular.

\section{Objective}

We wanted to address the specific question about what roles MICs can play in $\mathrm{DAH}$ and the more general question about criteria for identifying recipient and funding countries. Below, we initially focus on direct financial transfers and the criteria for identifying countries that should reasonably be net recipients and net funders, respectively. We first seek to clarify the fundamental issues involved and highlight a special feature of many MICs. We then examine allocation criteria and the identification of recipients, before addressing contribution norms and the identification of funders. In the final section, we conclude and offer some recommendations for decision makers.

\section{Importance}

Examining what roles the MICs can play is important because MIC is a category widely used today and because many believe that the role different countries should have in the DAH system can be usefully tied to their income class (reference to paper by Ottersen, Kamath, Moon, Martinsen and Røttingen in this series). According to the World Bank classification for the fiscal year 2015, countries with GNIpc $\leqslant$ \$1045 in 2013 are classified as LICs; countries with GNIpc \$1046-4125 and \$4126-12,745 as lower- and upper middle-income countries (LMICs and UMICs), respectively; and countries with GNIpc $\geqslant \$ 12,746$ as high-income countries (HICs) (World Bank, 2015). While this classification and the MIC category is commonly used, it is also widely agreed that MICs are very heterogeneous, and several categorisations of MICs have been offered. For example, one recent proposal categorises MICs in genuine MICs, premature MICs, post-Soviet 'bounce-back' MICs, and MICs with small populations (Sumner, 2016). Irrespective of their view on GNIpc per se, most people also seem to agree that the GNIpc classification thresholds are at least somewhat arbitrary and that the question about how these thresholds should be adjusted over time can be difficult. Nonetheless, examining the role of MICs can be highly instructive because a simple income classification may be a useful starting point for decisions on eligibility and allocation of DAH even if such a classification is imperfect and insufficient alone.

Answers to the specific question about MICs and the general question about criteria can have profound implications for individual countries and the DAH 
system as a whole. The importance of satisfactory answers is further underscored by the general economic downturn and the stagnation of DAH after a decade of unprecedented growth (IHME, 2016), the epidemiological transition and rise of non-communicable diseases, the increasing complexity of the DAH landscape, the ongoing work on the UN Sustainable Development Goals, and the upsurge of initiatives for new financing mechanisms for global health which require norms for which countries should contribute and how much (contribution norms) and criteria for which countries should receive funding and how much (allocation criteria) [Ooms et al., 2006; Consultative Expert Working Group (CEWG), 2012; Gostin, 2014] (reference to paper by Ottersen, Kamath, Moon, Martinsen and Rottingen in this series). The challenge posed by MICs also motivated the recent Equitable Access Initiative - a multi-partner initiative set to develop a new framework to classify countries and to guide global health investments (Equitable Access Initiative, 2015). Finally, contribution norms and allocation criteria can be as pivotal to the financing and provision of global public goods as to traditional DAH.

\section{The special feature of MICs}

The crux of the issue is a special feature of most MICs: mid-level GNIpc and substantial health needs and large inequalities. These characteristics will for most people pull in opposite directions. Mid-level GNIpc may suggest that MICs have the internal capacity to respond to domestic health needs, or at least greater capacity than LICs. Accordingly, one may hold that MICs have no claim on DAH and should be ineligible, or at least that DAH to MICs are less important than to LICs. Mid-level GNIpc may also suggest that many MICs can and should contribute significantly to DAH. On the other hand, substantial unmet health needs suggests that DAH to MICs is warranted, as meeting such needs is generally considered a central purpose of DAH. In fact, the absolute amount of unmet need and the number of individuals in need will often be greater in MICs than in LICs. Accordingly, one may hold that MICs have a claim on DAH and should be eligible, and perhaps even that DAH to MICs is equally or more important than to LICs. Balancing the concerns associated with GNIpc and unmet health needs is thus the crux of the issue, and this balancing act is a useful starting point for analysing the roles MICs can play and the criteria for identifying recipient and funding countries.

Table 1 highlights the points just made. It exhibits central characteristics of LICs, LMICs, UMICs, and HICs, as well as of some countries in each class. Beyond GNIpc, the characteristics include indicators related to need, inequality, health expenditure and DAH received. The 'cross' category emphasises four central relationships. GNI/U5M is the ratio of GNI to under-five mortality (U5M) while GNI/DALY is the ratio of GNI to the number of disability-adjusted life years (DALYs). Both ratios can be seen as a measure of a country's economic capacity to address needs per unit of unmet health needs. Correspondingly, 
Table 1. Key characteristics of low-income countries (LICs), middle-income countries (MICs) and high-income countries (HICs)

\begin{tabular}{|c|c|c|c|c|c|c|c|c|c|c|c|c|c|c|c|c|c|}
\hline & \multirow[b]{2}{*}{ Number } & \multirow[b]{2}{*}{$\begin{array}{l}\text { Population } \\
\text { (million) }\end{array}$} & \multirow{2}{*}{$\begin{array}{c}\text { Capacity } \\
\begin{array}{c}\text { GNIpc } \\
\text { (US\$) }\end{array}\end{array}$} & \multicolumn{3}{|c|}{ Need } & \multicolumn{3}{|c|}{ Inequality } & \multicolumn{2}{|c|}{ Expenditure } & \multicolumn{2}{|c|}{$\begin{array}{l}\text { Assistance } \\
\text { received }\end{array}$} & \multicolumn{4}{|c|}{ Cross } \\
\hline & & & & $\begin{array}{c}\% \text { in } \\
\text { poverty at } \\
\$ 2 / \text { day }\end{array}$ & $\begin{array}{c}\text { U5MR } \\
\text { (per } \\
1000)\end{array}$ & $\begin{array}{l}\text { DALY rate } \\
\text { (per 1000) }\end{array}$ & $\begin{array}{l}\text { Income share of } \\
\text { lowest } 10 \%(\%)\end{array}$ & $\begin{array}{l}\text { Gini } \\
\text { index }\end{array}$ & $\begin{array}{l}\text { U5MR ratio } \\
\text { across quintiles }\end{array}$ & $\begin{array}{l}\text { GHEpc } \\
\text { (US\$) }\end{array}$ & $\begin{array}{l}\text { GHE/ } \\
\text { GNI } \\
(\%)\end{array}$ & $\begin{array}{c}\text { DAH } \\
\text { (million } \\
\text { US\$) }\end{array}$ & $\begin{array}{c}\text { DAHpc } \\
\text { (US\$) }\end{array}$ & $\begin{array}{l}\text { GNI/U5M } \\
\text { (million) }\end{array}$ & $\begin{array}{l}\text { GNI/ } \\
\text { DALY } \\
\text { ('000) }\end{array}$ & $\begin{array}{l}\text { DAH/ } \\
\text { U5M } \\
\text { ('000) }\end{array}$ & $\begin{array}{l}\text { DAH/ } \\
\text { DALY }\end{array}$ \\
\hline LICs & 34 & 849 & 664 & 74 & 76 & 555 & na & na & na & 10 & 2.0 & 6498 & 8.0 & 0.2 & 0.6 & 2.9 & 15 \\
\hline Ethiopia & & 94 & 470 & 72 & 64 & 534 & 3.2 & 34 & 1.6 & 9 & 2.1 & 816 & 9.6 & 0.2 & 0.7 & 3.8 & 18 \\
\hline Tanzania & & 49 & 630 & 73 & 52 & 586 & 3.2 & 38 & 1.2 & 16 & 2.9 & 697 & 15.0 & 0.3 & 0.9 & 6.5 & 26 \\
\hline LMICs & 50 & 2561 & 2067 & 51 & 59 & 417 & na & na & na & 33 & 1.7 & 5113 & 2.1 & 1.5 & 4.1 & 1.4 & 5 \\
\hline India & & 1252 & 1570 & 61 & 53 & 416 & 3.7 & 34 & 3.0 & 20 & 1.3 & 933 & 0.8 & 1.4 & 3.1 & 0.6 & 2 \\
\hline Vietnam & & 90 & 1730 & 12 & 24 & 242 & 2.9 & 36 & na & 44 & 2.8 & 295 & 2.8 & 4.6 & 5.1 & 8.2 & 14 \\
\hline Ghana & & 26 & 1760 & 52 & 78 & 485 & 2.0 & 43 & 1.7 & 47 & 3.0 & 224 & 9.0 & 0.7 & 2.6 & 3.5 & 19 \\
\hline Nigeria & & 174 & 2710 & 82 & 117 & 795 & 2.2 & 43 & 2.5 & 29 & 1.2 & 757 & 4.6 & 0.6 & 1.8 & 0.9 & 6 \\
\hline Indonesia & & 250 & 3580 & 43 & 29 & 303 & 3.4 & 36 & 2.5 & 43 & 1.2 & 223 & 0.9 & 6.4 & 8.3 & 1.5 & 3 \\
\hline UMICs & 55 & 2409 & 7594 & 14 & 20 & 266 & na & na & na & 248 & 3.7 & 2836 & 1.2 & 24.1 & 22.5 & 3.7 & 4 \\
\hline Thailand & & 67 & 5370 & 4 & 13 & 280 & 2.8 & 39 & na & 164 & 3.1 & 86 & 1.2 & 39.1 & 15.4 & 8.6 & 5 \\
\hline China & & 1357 & 6560 & 19 & 13 & 244 & 1.7 & 42 & na & 180 & 3.1 & 207 & 0.2 & 42.7 & 17.0 & 0.9 & 1 \\
\hline South Africa & & 53 & 7190 & 26 & 44 & 653 & 1.1 & 65 & na & 309 & 4.1 & 666 & 13.2 & 7.8 & 9.1 & 12.8 & 20 \\
\hline Colombia & & 48 & 7560 & 12 & 17 & 255 & 1.1 & 54 & 2.2 & 402 & 5.7 & 114 & 2.4 & 23.4 & 21.4 & 6.9 & 10 \\
\hline Brazil & & 200 & 11,690 & 7 & 14 & 277 & 1.0 & 53 & na & 490 & 4.2 & 175 & 0.9 & 56.4 & 34.3 & 3.8 & 3 \\
\hline HICs & 76 & 1175 & 42,881 & na & 7 & 267 & na & na & na & 3170 & 7.5 & 0 & 0 & 527.0 & 125.3 & 0 & 0 \\
\hline UK & & 64 & 42,040 & na & 5 & 271 & 2.9 & 33 & na & 3025 & 7.4 & 0 & 0 & 715.4 & 141.9 & 0 & 0 \\
\hline Norway & & 5 & 104,130 & na & 3 & 248 & 3.6 & 26 & na & 7947 & 8.0 & 0 & 0 & 3148.5 & 350.1 & 0 & 0 \\
\hline
\end{tabular}

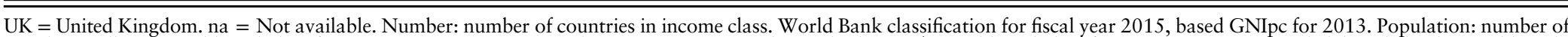

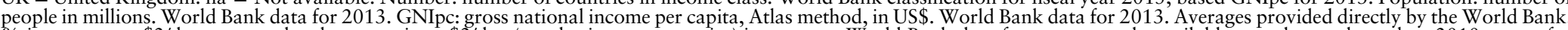
$\%$ in poverty at \$2/day: poverty headcount r at \$2/day (purchasing power parity) in per cent. World Bank data for most recently available year, but no later than 2010 except for

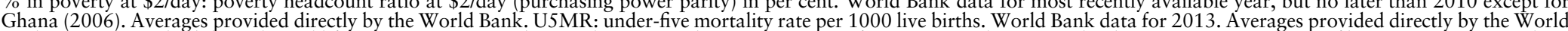
Bank. DALY rate: disability-adjusted life years per 1000 people. Based on IHME data on DALY rate for 2010. Population-weighted averages. Income share of lowest $10 \%$ : income share held by the $10 \%$ of the population with the lowest income, in per cent. World Bank data for most recently available year, but no later than 2010 except for India (2009) and Ghana (2006).

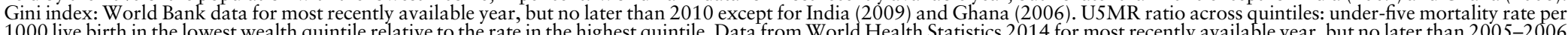

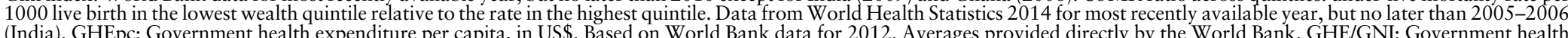

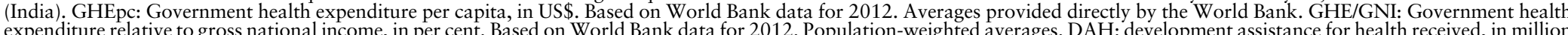

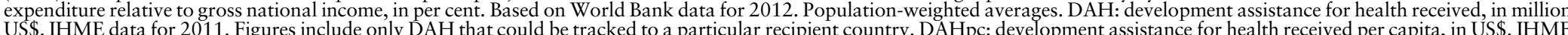
S\$. IF data for 2011. Figures ind that could be tracked to a particular recipientar recipient country. DAHpc: deverages based on World Bank data on population for 2011. GNI/

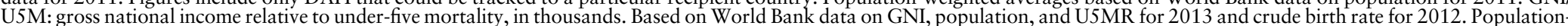
weighted averages. GNI/DALY: gross national income relative to disability-adjusted life years, in thousands. Based on World Bank data on GNI for 2010 and IHME data on DALYs for 2010. Population-weighted averages. DAH/U5M. development assistance for health received relative to under-five mortality. Based on IHME data on DAH for 2011 and W/orld Bank data

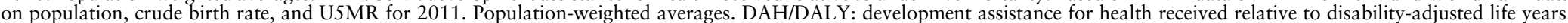
Based on IHME data on DAH for 2011 and DALYs for 2010. Population-weighted averages. 
DAH/U5M and DAH/DALY can be seen as measures of DAH per unit of unmet health needs.

Table 1 indicates how GNIpc and unmet health needs tend to be inversely correlated, but also that this trend has important exceptions, given that several countries have greater needs than countries with lower GNIpc. Apart from intercountry relations, Table 1 also demonstrates the substantial unmet needs in LMICs and even UMICs. South Africa, for example, has a GNIpc that places it well within the UMIC class, while U5MR is very high and higher than in several LMICs and even in some LICs (not shown). Moreover, the severe situation of certain populations stands out even clearer if one also considers the ratio of U5MR in the lowest and highest wealth quintile. In India, for example, that ratio is as high as three. When it comes to the cross categories, there is also clear trends across GNIpc and countries categories, as well as important exceptions. For example, while Brazil has a national income of 56 million/child death, Ethiopia has only 0.2 million. Ethiopia has thus arguably a much lower capacity to address these deaths and may be in greater need of development assistance. With regard to $\mathrm{DAH}$, one clear example of cross-country variation is how Vietnam receives almost 14 times more DAH per child death than India, despite the two countries having similar GNIpc.

\section{Allocation criteria and identification of recipients}

When considering the role of MICs in the DAH system, it is natural to start examining the relevance of GNIpc.

\section{National income and capacity}

Today, GNIpc is a prominent criterion for identifying recipients and for determining the amount of DAH to be received (reference to paper by Ottersen, Kamath, Moon, Martinsen and Røttingen in this series). The central role of GNIpc criteria can be explained by the quantitative and objective nature of GNIpc, the availability of data, and its relationship to overarching objectives and criteria for development assistance. For development assistance in general, GNIpc can be an indicator of development need, effectiveness and capacity. For DAH, the link to capacity is likely to be most relevant. While national income may be seen as integral to general development need, DAH is primarily concerned with unmet health needs. As is well known, GNIpc is correlated with many health outcomes, including life expectancy, but the correlation between GNIpc and health needs is far from perfect, as is indicated in Table 1 and Figure 3. Similarly, DAH is primarily concerned with effectiveness in terms of improvements in health outcomes, and a consistent link between GNIpc and such improvements has yet to be established. Development assistance may be more effective in MICs than in LICs, but the relationship between level of GNIpc and effectiveness of 
development assistance is clearly not a straightforward one (Glennie, 2011; Verbeke and Renard, 2011; Kanbur and Sumner, 2012; Glassman et al., 2013; Alonso et al., 2014; Glennie and Sumner, 2014).

Higher GNIpc generally indicates greater domestic capacity, where domestic capacity is understood as the country's ability to address needs without external support. This understanding is in line with many other definitions of capacity, and capacity so understood relates to ability to pay, fiscal space and absence of financial constraints (Reddy and Heuty, 2004; Knack et al., 2012; Glassman et al., 2013; Resch et al., 2015). Capacity as the ability to meet needs without external support is different from absorptive capacity, which is the country's ability to effectively make use of such support.

GNIpc is a broader capacity indicator than both general government expenditure per capita (GGEpc) and government health expenditure per capita (GHEpc). This is underscored by the fact that governments have numerous levers at their disposal to raise the levels of GGEpc and GHEpc even for a given level of GNIpc (reference to paper by Elovainio and Evans; paper by Meheus and McIntyre; and paper by McCoy, Chigudu and Tillmann in this series).

The idea that higher GNIpc indicates greater capacity can be combined with the generally acknowledged principle that countries with greater capacity have less claim on external support. This principle is sometimes motivated by ideals for allocating aid on the basis of responsibility, desert or equality of opportunity among countries (Llavador and Roemer, 2001; Cogneau and Naudet, 2007). However, if individuals are our ultimate unit of concern, it is equality of opportunity among individuals that really matters. Nevertheless, holding countries responsible for reasons related to incentives can be compatible with this. The very activity of holding states responsible - including allocating less DAH to countries with higher GNIpc - may reduce perverse incentives and moral hazard, and induce higher domestic health spending, with positive consequences for individuals overall. Conversely, if states qualify for DAH irrespectively of GNIpc and their capacity to address domestic health needs, they may not be motivated to invest sufficiently in health and health services. This mechanism is discussed extensively in several bodies of literature, including those on aid conditionality and aid dependency (Svensson, 2000; Gibson et al., 2005).

\section{Identifying capacity thresholds}

Given the preceding discussion, it is relevant to explore how a general GNIpc threshold may be specified from a capacity perspective. This can be done by considering the minimum GNIpc necessary to ensure priority services for different levels of effort. Such an attempt is bound to be crude, but a general threshold based on concerns for capacity or otherwise - can be useful in practice even if imperfect and insensitive to many country particularities. The approach outlined 
can also provide a framework for reasoning and starting point for further discussion and for adjustments of thresholds.

From a capacity perspective, the search for a threshold may start by asking what minimum level of GNIpc that is required for a country to ensure priority services for everyone if it exerts very high effort. This level can be sought by way of two steps. First, one estimates the minimum level of GHEpc typically required to ensure priority services for everyone. The 2001 Commission on Macroeconomics and Health $(\mathrm{CMH})$ and the 2009 Task Force for Innovative International Financing for Health Systems (HLTF) have provided such estimates for total health expenditure per capita (THEpc) (CMH, 2001; HLTF, 2009). A recently updated estimate based on the HLTF methodology suggests that GHEpc of $\$ 86^{1}$ (in both 2012 and 2015 terms) is the minimum expenditure required in 2015 to ensure priority services for everyone the context of LICs (reference to paper by McIntyre, Meheus and Røttingen in this series). ${ }^{2}$ The rationale for seeing $\$ 86$ as a target for GHEpc rather than THEpc is that in order to ensure universal health coverage (UHC) of priority services for everyone, the $\$ 86$ would probably need to come from mandatory, prepaid, pooled funds rather than from private spending.

The second step is to exploit the link between country effort and the ratio of GHE to GNI. A reasonable estimate of what ratio that indicates very high effort is the upper centile for LICs and MICs when ranked from lowest to highest. For 2012 , the upper centile ratio was $6.1 \%{ }^{3}$ The minimum GNIpc required to ensure priority services for everyone given very high effort can then be estimated by dividing the minimum GHEpc, that is $\$ 86$, by the upper centile ratio, which gives a GNIpc of $\$ 1410$ (2012). It is important to note that the GNIpc and GHEpc estimates used are not adjusted for purchasing power parity (PPP), which is in line with the World Bank classification and most eligibility thresholds and allocation policies employed today. Use of PPP-based estimates is likely to have generated different results, and the advantages and disadvantages of such measures are extensively discussed elsewhere.

The upshot of the two-step procedure is that countries below $\$ 1410 \mathrm{GNIpc}$ will be unable to ensure priority services for everyone, even if they exert very high effort (by dedicating $6.1 \%$ or more of GNI to health). From a capacity perspective, it may thus be good reasons to consider all these countries eligible for DAH and reasonable net recipients. Accordingly, $\$ 1410$ may be what we can call the lower capacity threshold. Its relations to other thresholds are illustrated in Figure 1.

Even if one believes that every country below the lower capacity threshold should be eligible, it may not be appropriate to consider every country above that threshold ineligible. One reason is that very high effort, by any reasonable standard, can

1 All dollar amounts in this article is in US dollars.

2 While the corresponding estimates for MICs are likely to be higher, partly due to higher price levels, we will use that estimate throughout.

3 Based on World Bank data. Only countries with available GNIpc estimates for 2012 were included, except Cuba (2011). These ratios are partly influenced by external funding and funders' priorities. 


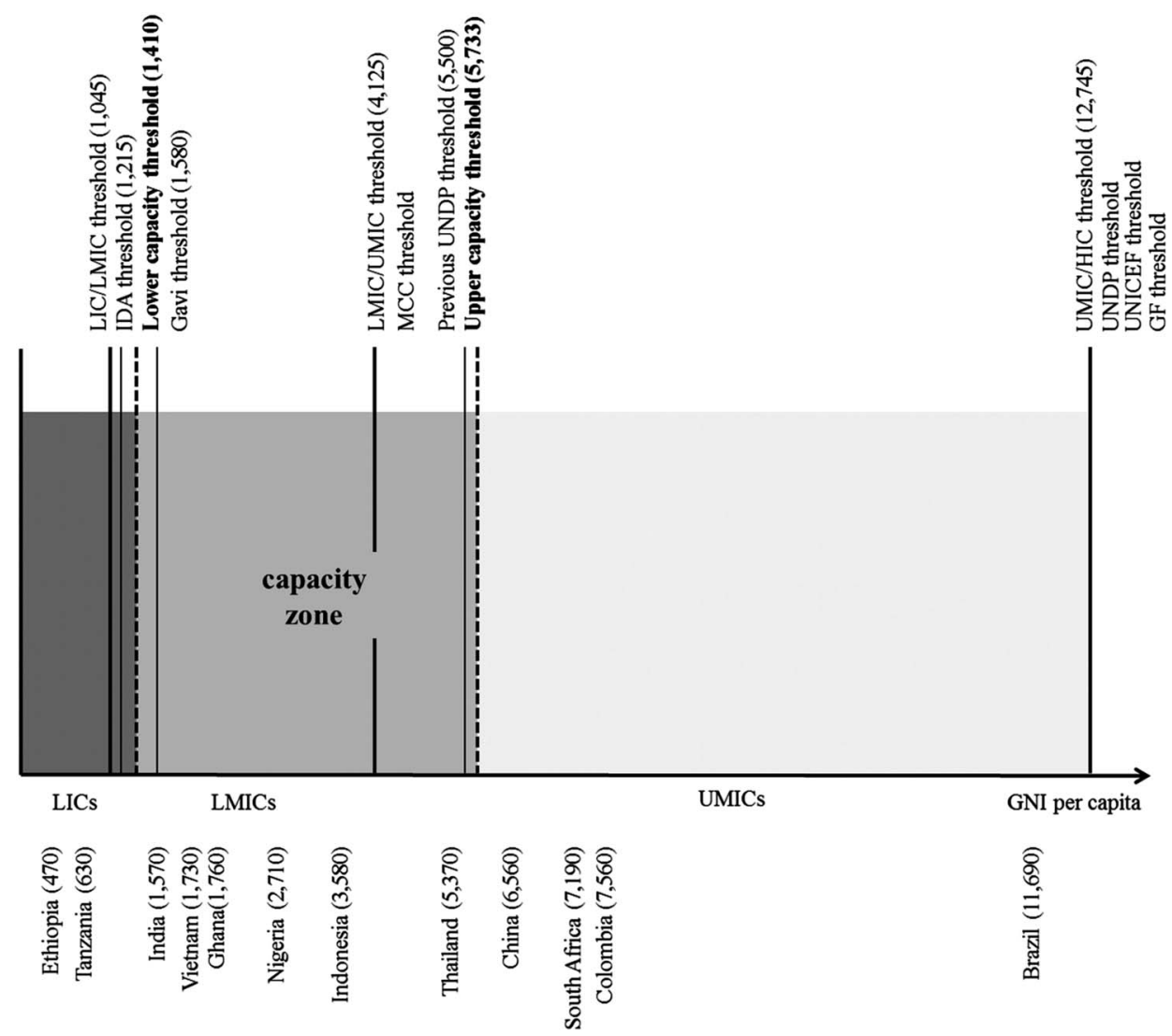

Figure 1. Eligibility thresholds and gross national income per capita (GNIpc) of selected countries.

Explanation: income classification thresholds are based on the World Bank classification for fiscal year 2015. GNIpc figures are based on World Bank data for 2013 (Atlas method). All figures are in US\$. GNI = gross national income; LICs = low-income countries; LMICs = lower $\quad$ middle-income countries; $\quad$ UMICs = upper middle-income countries; IDA $=$ The International Development Association; $\mathrm{MCC}=$ The Millennium Challenge Corporation; UNDP $=$ The United Nations Development Programme; UNICEF $=$ The United Nations Children's Fund; GF = The Global Fund to Fight AIDS, Tuberculosis and Malaria.

translate into a GHE/GNI ratio lower than $6.1 \%$ if the circumstances are difficult enough. The set of barriers which countries face in their pursuit of social objectives are not fully captured by GNIpc. Generally, it may also be easier to secure a certain share of GNIpc for health, the higher GNIpc is, although evidence suggests that both the ratio of general government expenditures to GNI and the share of general government expenditures being devoted to health are largely matters of political choice (reference to paper by Meheus and McIntyre and paper by Elovainio and Evans in this series). In addition, we may not want to strictly require very high effort for countries to be eligible. Accordingly, we may want to 
identify a capacity-related threshold above which countries generally should be considered ineligible.

We may identify such a threshold by asking what minimum level of GNIpc that is required for a country to ensure priority services for everyone if it exerts very low effort. The ratio that represents very low effort can be identified as the lower centile for LICs and MICs when ranked from lowest to highest. For 2012, the lower centile ratio was $1.5 \%$. The minimum GNIpc required to ensure GHEpc of $\$ 86$ and priority services for everyone if a country exerts very low effort can then be estimated to a GNIpc of $\$ 5733$ (2012). From a capacity perspective, it then appears to be good reasons for considering countries with a GNIpc above this level generally ineligible for DAH - because all countries with GNIpc above this level can be seen to have the capacity to ensure priority services for everyone without external support. We may call this the upper capacity threshold. Its relations to other thresholds are illustrated in Figure 1.

Also the upper capacity threshold may be challenged for being too restrictive, for a range of reasons. One could be that the role of DAH goes beyond GHEpc of $\$ 86$. On the other hand, the upper capacity threshold may be challenged for being too liberal and too damaging to incentives. The optimal threshold, from a capacity perspective, may thus lie somewhere in between the lower and upper capacity thresholds. Between these two thresholds, we may speak of a 'capacity zone'. The capacity thresholds and the capacity zone are illustrated in Figure 1. That figure also exhibits the thresholds used in the World Bank income classification, thresholds used by some major funders of DAH, and the GNIpc for the countries listed in Table 1.

As indicated by the figure, the entire capacity zone falls within the GNIpc range for MICs. Accordingly, from a capacity perspective, there are reasons to suggest that some MICs should be eligible for DAH while other MICs should not. Specifically, with respect to capacity, there seems to be a case for all LICs and most LMICs to be eligible and most UMICs to be ineligible.

\section{Health needs}

To address health needs is typically considered a central purpose of DAH, and most discussions on the allocation of DAH centre on health needs (Bell and Fink, 2005; Gostin, 2014; IHME, 2016). There is a strong case for a country's legitimate claim to DAH to increase with unmet health needs, and there is a strong imperative to attend to individual health needs wherever they are. This suggests that health needs should be taken directly into account and that GNIpc is an insufficient basis for identifying DAH recipients. Health needs may be considered on a country-by-country basis, but we may also want to adjust the general GNIpc threshold - based a concerns for capacity or otherwise - for such needs.

There are several reasons why one may want to adjust the general eligibility threshold for health needs. Most fundamentally and as just described, there is 
a case for attending to unmet health needs wherever these are, and this have also been put forward as a key reason to support MICs, including UMICs. In addition, the legitimacy of the DAH system may partly depend on it being relevant to a significant share of total health needs. Figure 2 shows the total number of underfive deaths that is excluded from the scope of DAH across the range of possible GNIpc thresholds. These thresholds are applied to countries and thus not directly sensitive to internal income inequalities.

Figure 2 shows that as many as 3.6 million under-five deaths $(56 \%)$ fall outside the remit of DAH if the lower capacity threshold $(\$ 1410)$ is applied, while the number is substantially reduced, to $582,000(9 \%)$, if the upper threshold $(\$ 5733)$ is used. The number of under-five deaths excluded from DAH dips at GNIpc of $\$ 1570$, $\$ 2710$ and $\$ 6560$; dips caused by India, Nigeria, and China. A similar pattern is seen for disease burden in terms of DALYs. If it is important not to exclude a major amount and share of health needs from the scope of DAH, there is a reason to have a threshold that is at least somewhat above the lower capacity threshold.

Another reason why one may want to adjust thresholds for health needs has to do with the ratios between capacity, as proxied by GNIpc, and health needs across countries. One may think that countries with low ratios should fall within the reach of DAH even when they are capable - according to the reasoning described above - to meet unexceptional health needs over time. Moreover, the ratios between GNIpc and health needs may be relevant for fairness. It may seem unfair if some ineligible countries have considerably higher ratios than some eligible countries. Figure 3 shows the GNI/U5M and GNI/DALY ratio for LICs and MICs with GNIpc below the upper capacity threshold.

Figure 3 shows that while the GNI/U5M and GNI/DALY ratios have a general upward trend over GNIpc, there is considerable variation by country. The pattern does not by itself suggest any obvious threshold. Instead, the figure underscores the obvious point that, in addition to a general threshold, one may want eligibility and allocation criteria to be more sensitive to country particularities. Accordingly, one would like to make the GNIpc threshold part of the eligibility criteria in a way that can both take such particularities into account and properly integrate the concerns for capacity and need.

\section{Further integration of capacity and need}

A single eligibility threshold motivated by concerns for capacity and incentives and generally adjusted for health needs may only be the first step towards balancing capacity and needs. Further integration can be done by the parallel use of needs-based exceptions and incentive-preserving instruments. The latter are methods that help preserve countries' incentives to address domestic health needs themselves. Such exceptions and instruments are used by some DAH funders already, but a review of major funders showed that many funders did not have criteria explicitly linked to health needs or to inequalities (reference to paper by 


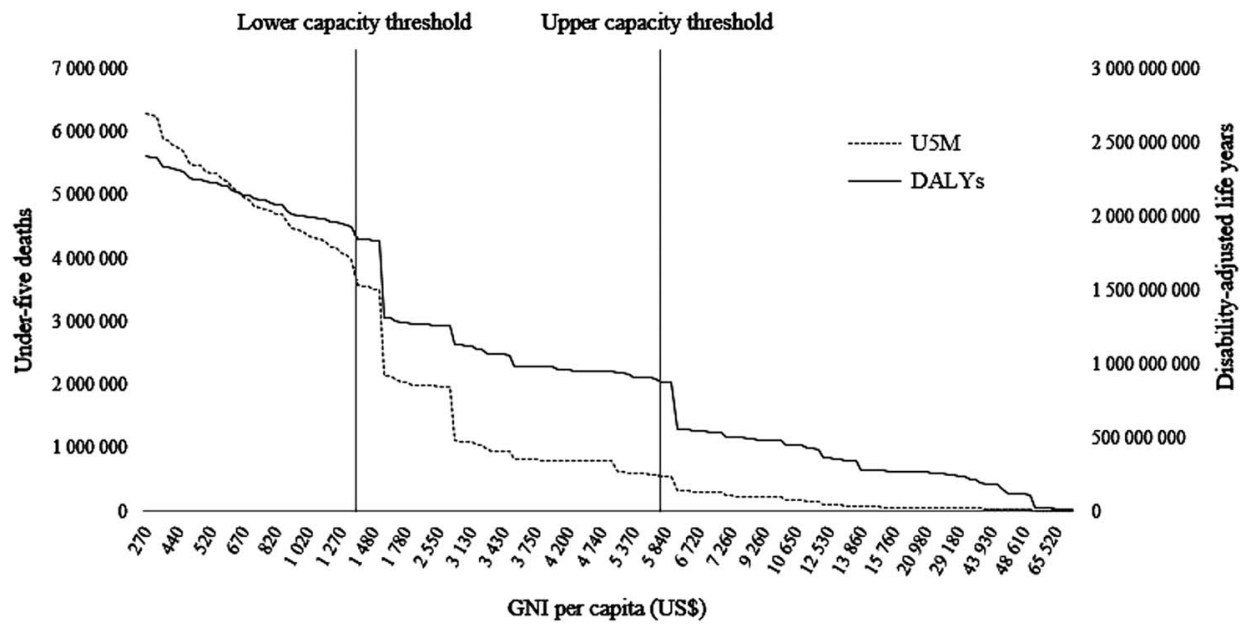

Figure 2. Total under-five deaths and disability-adjusted life years (DALYs) excluded from the scope of DAH for different country-eligibility thresholds.

Explanation: based on World Bank data on gross national income (GNI), population, and under-five mortality rate (U5MR) for 2013, World Bank data on crude birth rate for 2012, and on IHME data on DALYs for 2010. Countries for which data were unavailable were excluded.

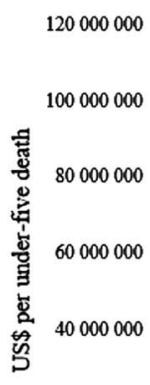

20000000

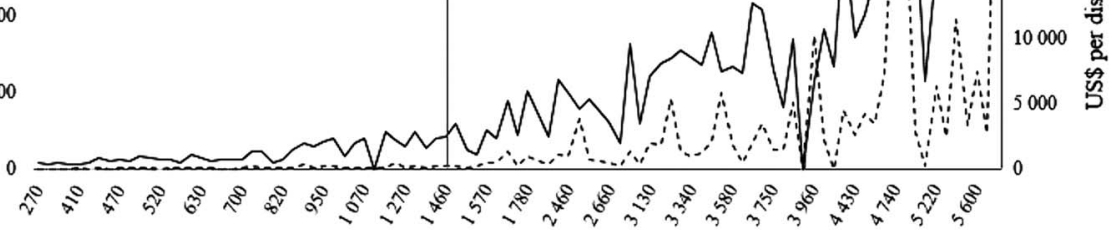

GNI per capita (US\$)

Figure 3. Ratio of gross national income (GNI) to under-five mortality (U5M) and ratio of GNI to disability-adjusted life years (DALYs) for countries below the upper capacity threshold.

Explanation: GNI/U5M ratio based on World Bank data on GNI, population, and under-five mortality rate for 2013 and on crude birth rate for 2012. GNI/DALY ratio based on World Bank data on GNI for 2010 and IHME data on DALYs for 2010. Countries for which data were unavailable were excluded. 
Ottersen, Kamath, Moon, Martinsen and Røttingen in this series), and there seems to be great potential in a more careful integration of capacity and health needs more generally. The challenge here, however, is to find the best compromise between a single, over-simplistic threshold and a complex, opaque set of differentiated criteria with multiple exceptions.

There are several types of health needs that may trigger exceptions. Most obviously, exceptions may be warranted by poor aggregate health outcomes in the country, linked to measures such as mortality rates or DALYs. Alternatively, exceptions can be linked to a specific relation between health needs and capacity in terms of GNIpc. For example, ratios of GNI relative to U5M and DALYs are shown in Table 1 and Figure 3. Some funders already consider such ratios when allocating development assistance (reference to paper by Ottersen, Kamath, Moon, Martinsen and Røttingen in this series). For example, UNICEF uses an allocation formula with GNIpc, U5MR and child population as the central arguments. The Global Fund also uses a kind of need-based exceptions in determining eligibility as UMICs are only eligible if their burden from the disease in question is 'high', 'severe' or 'extreme'.

Given the nature of the challenge posed by MICs, needs-based exceptions should probably go beyond country averages and account for the needs of subpopulations (Kanbur and Sumner, 2012). For example, countries that have subpopulations with severe health needs may be considered eligible even when GNIpc is above the standard threshold and average population health is fairly adequate. As indicated by Table 1, India and South Africa could be reasonable candidates for exceptions based on subpopulation needs if the chosen standard threshold otherwise would make them ineligible. Moreover, irrespectively of whether one compares the needs of countries or subpopulations, it may be necessary to go beyond the current state to also consider the risks for greater needs in the future. These risks may include emerging epidemics and other infectious disease threats.

With needs-based exceptions, the issue of incentives reappears, although in a different form. It will therefore be useful to combine such exceptions with instruments for preserving countries' incentives to properly address domestic health needs themselves. As indicated above, this is essential because the countries' own spending on health is likely to depend on the criteria used by funders to allocate DAH and the allocated amounts. In particular, there is evidence suggesting that DAH may displace some domestic financing for health (reference to paper by Moon and Omole in this series).

Numerous considerations are relevant when designing incentive-preserving instruments. Many of these have been widely discussed in the general literature on aid conditionality (Gibson et al., 2005; Koeberle et al., 2005; Temple, 2010). The design of an effective incentive-preserving-instrument scheme requires in particular four careful choices. One key choice is whether incentive-preserving instruments should be primarily linked to policies (inputs), outputs or outcomes. Potentially relevant policy aspects include budget composition and government health 
expenditures, and service coverage rates are among the potentially relevant outputs. For example, both the Global Fund and Gavi uses co-financing requirements, and, for most kinds of support, Gavi also requires that coverage for the third dose of the pentavalent vaccine diphtheria, tetanus, pertussis, hepatitis B and Haemophilius influenzae type B (Penta3) is equal to or above $70 \%$ (reference to paper by Ottersen, Kamath, Moon, Martinsen and Røttingen in this series). A second key choice is whether incentive-preserving instruments should be ex ante or expost, where the latter links funding to demonstrated achievements. Many funders currently experiment with various results-based or performance-based aid schemes, but there is still no agreement on whether and when these schemes work (Paul, 2015; Perakis and Savedoff, 2015; Silverman et al., 2015). A third choice is the extent to which the incentive-preserving instruments should depend on the state of affairs at a given point in time or on improvements over time. While the former is more common, it has been argued that linking conditionality to improvements can be crucial for incentives (Öhler et al., 2012). A fourth choice, which is particularly important in the context of MICs, is the degree of targeting (Kanbur, 2016). Incentive-preserving instruments can be specifically linked to addressing the needs of subpopulations or reduction of inequalities. For example, the Global Fund requires that LMICs and UMICs focus at least 50 or $100 \%$, respectively, of the funding on key and vulnerable populations, 'highest impact interventions', or both (reference to paper by Ottersen, Kamath, Moon, Martinsen and Røttingen in this series).

Beyond these incentive-preserving instruments, funders may of course employ broader requirements, which are not specifically linked to exceptions. Among other things, funders could require a certain level of de facto effort for a country to be eligible irrespectively of whether or not a high level of effort would be sufficient to meet health needs. In any case, there are many well-known challenges related to aid conditionality in general, including challenges of ensuring compliance and of respecting country ownership (Gibson et al., 2005; Koeberle et al., 2005; Temple, 2010), and some of these apply to incentive-preserving instruments. This underscores the need for DAH funders to carefully examine their criteria and seek ways to better balance the concerns for capacity and health needs.

\section{Contribution norms and identification of funders}

So far, we have addressed criteria for being eligible as a recipient of DAH, understood as criteria for reasonably being a net recipient. These criteria do not automatically tell which countries should be net funders. Reasonable criteria for identifying recipients and funders share, however, a central concern for capacity or ability to pay.

\section{National income and capacity}

Capacity to pay, and specifically national income, is central to many, if not most, contribution norms. One prominent example is the well-known 0.7 ODA/GNI 
target, which is based on GNI (Pearson et al., 1969). Another is the United Nations scale of assessments, which is based on both GNI and GNIpc [United Nations General Assembly (UNGA), 2012].

Also in the specific context of assistance for health, it is reasonable that the criteria for identifying required net funders are at least partly based on capacity and national income. Accordingly, we may want a GNIpc funder threshold similar in kind to the eligibility threshold. The eligibility threshold is also a useful starting point for specifying the funder threshold, but there are at least four reasons why the latter may be set considerably higher than the former. Most obviously, one may want to be fairly confident that countries do have the capacity to ensure priority services for everyone domestically before calling on them to become net funders. Second, it is preferable with a smooth transition from net recipient status to net funder status (Salvado and Walz, 2013). Third, various transactions costs (Acharya et al., 2006; Paul and Vandeninden, 2012) may suggest that the differences between recipients and funders should be significant in most cases. Fourth, countries may have a legitimate prerogative to privilege their own population to some, yet limited extent. This may go beyond any practical considerations as many, if not most, theories of global justice do leave space for such a prerogative (Johri et al., 2012).

This set of reasons motivates a transition zone, that is, a range of GNIpc in which countries are neither eligible for DAH nor required net funders. This zone may extend from the chosen eligibility threshold to a significantly higher level of GNIpc, as illustrated in Figure 4. As for the eligibility threshold, need-based exceptions can be attached to the funder threshold.

These thresholds suggest that all or most LMICs should not be net funders, while most UMICs should be.

\section{Rationale for being both funder and recipient}

One of the seemingly paradoxical features of today's situation is that several major recipients of DAH are also increasingly significant funders (GHSi, 2012; IHME, 2016). For example, India and South Africa were among the top 10 recipients of DAH in 2011, but provided $\$ 1100$ and $\$ 212$ million in foreign assistance in 2013 (GHA, 2014).

That some recipients of DAH also provide foreign aid can, of course, be explained by various strategic political and economic interests. However, from a system perspective, joint funder and recipient status may often be inefficient due to transaction costs (Acharya et al., 2006; Paul and Vandeninden, 2012). At the same time, there are reasons to suggest that such a joint status may be beneficial even for the DAH system as a whole under certain circumstances. In particular, this may the case when DAH goes beyond direct financial transfer to include some form of knowledge transfer and when certain DAH recipients do have special expertise relevant for other countries (Glennie, 2011; Verbeke and Renard, 2011; 

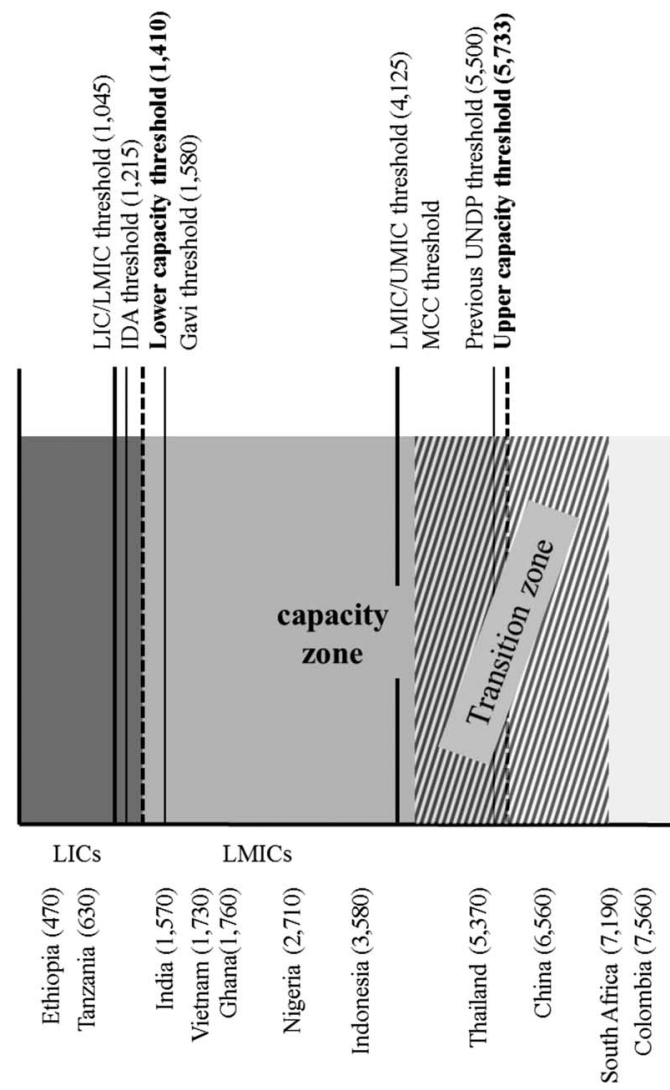

UMICs

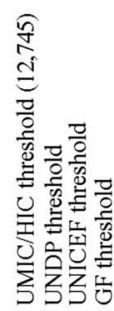

Figure 4. Eligibility thresholds, gross national income per capita of selected countries, and possible transition zone.

Explanation: income classification thresholds are based on the World Bank classification for fiscal year 2015. GNIpc figures are based on World Bank data for 2013 (Atlas method). All figures are in US\$. GNI = gross national income; LICs = low-income countries; LMICs = lower middle-income countries; UMICs = upper middle-income countries; IDA $=$ The International Development Association; $\mathrm{MCC}=$ The Millennium Challenge Corporation; UNDP = The United Nations Development Programme; UNICEF $=$ The United Nations Children's Fund; GF = The Global Fund to Fight AIDS, Tuberculosis and Malaria.

Glassman et al., 2013). Perhaps most clearly, countries that have recently made progress may hold unique lessons for other countries. Thailand and Mexico, for example, have recent experience with successful health reform and progress towards UHC, and their insights can be valuable for many other countries (Hughes and Leethongdee, 2007; Knaul et al., 2012). In addition, many countries that are DAH recipients may have special expertise in the development and production of low-cost delivery technologies. Accordingly, DAH in the form of knowledge transfer and technical support can sometimes be usefully provided by net recipients and usefully received by net funders. 


\section{Conclusion}

The role of MICs in the DAH system is a complex issue which also raises fundamental questions about the criteria for allocating DAH among countries and the norms for which countries should contribute and how much. This gives reason for major actors in the DAH system to critically examine their current criteria and norms, and this paper has offered a framework for doing this. Funders may also want to consider projections for economic growth and the geography of poverty, as a majority of the world's poor may again be located in LICs in the future. More specifically, we offer four recommendations to these actors.

First, it is useful to focus on the central trade-off between the concerns for capacity and incentives and the concern for meeting health needs everywhere. If a single GNIpc eligibility threshold is desired for coherence and simplicity, the capacity-based approach illustrated in this paper suggests a threshold between $\$ 1410$ and \$5733. To the extent that this is reasonable, these thresholds suggest that all LICs and most or all LMICs should be eligible, while most or all UMICs should be ineligible. From the perspective of these illustrative thresholds, funders such as Gavi and IDA could consider raising their threshold, while funders such as the Global Fund, UNICEF and UNDP could consider lowering their threshold.

Second, while maintaining simplicity and transparency, it may be optimal to combine a single general GNIpc eligibility threshold with a limited set of needs-based exceptions and incentive-preserving instruments. The exceptions and the instruments should plausibly pay particular attention to inequalities, the needs of subpopulations, and other special health needs.

Third, relevant decision makers may implement a funder threshold at a GNIpc level significantly higher than for the eligibility threshold. This will imply that some MICs can reasonably be neither net recipients nor net funders. The capacitybased approach illustrated in this paper suggests a funder threshold that requires none or few LMICs to contribute significantly to DAH, but most UMICs to do so.

Fourth, decision makers should probably acknowledge that certain countries can usefully be both recipients and funders, especially when DAH goes beyond direct financial transfers.

In short, the role MICs should play in the DAH system is likely to be diverse. Some may mainly be recipients, some may mainly be funders, some may be both recipients and funders, and some neither. A simple, yet adequately nuanced approach to MICs can help ensure that DAH is mobilised and allocated to meet health needs in a complex global landscape.

\section{Acknowledgements}

The authors are grateful to the members of the Working Group on Health Financing at Chatham House Centre on Global Health Security and to Joseph Dieleman, Amanda Glassman, and Andrew Sumner for their helpful comments. 


\section{References}

Acharya, A., A. T. F. de Lima and M. Moore (2006), 'Proliferation and fragmentation: transactions costs and the value of aid', Journal of Development Studies, 42(1): 1-21.

Alonso, J. A., J. Glennie and A. Sumner (2014), Recipients and Contributors: Middle Income Countries and the Future of Development Cooperation, New York: Department of Economic and Social Affairs, United Nations.

Bell, C. and C. Fink (2005), 'Aid and Health'. Development Aid: Why and How? Towards Strategies for Effectiveness, Paris: Agence Française de Développement, 163-190.

Cogneau, D. and J.-D. Naudet (2007), 'Who deserves aid? Equality of opportunity, international aid, and poverty reduction', World Development, 35(1): 104-120.

Commission on Macroeconomics and Health (CMH) (2001), Macroeconomics and Health: Investing in Health for Economic Development, Geneva: World Health Organization.

Consultative Expert Working Group (CEWG) (2012), Research and Development to Meet Health Needs in Developing Countries: Strengthening Global Financing and Coordination Consultative Expert Working Group on Research and Development: Financing and Coordination Geneva: World Health Organization.

Equitable Access Initiative (2015), 'Updated - Terms of reference for the Equitable Access Initiative', http://www.theglobalfund.org/documents/eai/EAI_EquitableAccessInitiative_ ToRs_en/ [28 June 2015].

Gibson, C. C., K. Andersson, E. Ostrom and S. Shivakumar (2005), The Samaritan's Dilemma: The Political Economy of Development Aid, Oxford: Oxford University Press.

Glassman, A., D. Duran and A. Sumner (2013), 'Global health and the new bottom billion: what do shifts in global poverty and disease burden mean for donor agencies?', Global Policy, 4(1): 1 .

Glennie, J. (2011), The Role of Aid to Middle-Income Countries: A Contribution to Evolving EU Development Policy Working Paper 331 London: Overseas Development Institute.

Glennie, J. and A. Sumner (2014), 'The \$138.5 billion question: when does foreign aid work (and when doesn't It)?', CGD Policy Paper 049. Center for Global Development, Washington, DC.

Global Humanitarian Assistance (GHA) (2014), 'Country profiles: overview', Development Initiatives, http://www.globalhumanitarianassistance.org/country-profiles [5 December 2014].

Global Health Strategies initiatives (GHSi) (2012), Shifting Paradigm: How the BRICS are Reshaping Global Health and Development, New York: Global Health Strategies initiatives.

Gostin, L. O. (2014), Global Health Law, Cambridge, MA: Harvard University Press.

Hughes, D. and S. Leethongdee (2007), 'Universal coverage in the land of smiles: lessons from Thailand's 30 baht health reforms', Health Affairs, 26(4): 999-1008.

Institute of Health Metrics and Evaluation (IHME) (2016), Financing Global Health 2015: Development Assistance Steady on the Path to New Global Goals, Seattle, WA: Institute of Health Metrics and Evaluation.

Johri, M., R. Chung, A. Dawson and T. Schrecker (2012), 'Global health and national borders: the ethics of foreign aid in a time of financial crisis', Globalization and Health, 8(19): 1-10.

Kanbur, R. (2016), 'Can a Country be a Donor and a Recipient of Aid?', in S. M. Dev and P. G. Babu eds Development in India: Micro and Macro Perspectives, New Delhi: Springer India, 71-81.

Kanbur, R. and A. Sumner (2012), 'Poor countries or poor people? Development assistance and the new geography of global poverty', Journal of International Development, 24: 686-695. 
Knack, S., F. H. Rogers and J. C. Heckelman (2012), 'Crossing the threshold: a positive analysis of IBRD graduation policy', Review of International Organizations, 7: 145-176.

Knaul, F. M., E. González-Pier, O. Gómez-Dantés, D. García-Junco, H. Arreola-Ornelas, M. Barraza-Lloréns, R. Sandoval, F. Caballero, M. Hernández-Avila, M. Juan, D. Kershenobich, G. Nigenda, E. Ruelas, J. Sepúlveda, R. Tapia, G. Soberón, S. Chertorivski and J. Frenk (2012), 'The quest for universal health coverage: achieving social protection for all in Mexico', Lancet, 380: 1259-1279.

Koeberle, S., H. Bedoya, P. Silarszky and G. Verheyen (eds) (2005), Conditionality Revisited: Concepts, Experiences, and Lessons, Washington, DC: World Bank.

Llavador, H. G. and J. E. Roemer (2001), 'An equal-opportunity approach to the allocation of international aid', Journal of Development Economics, 64: 147-171.

Ooms, G., K. Derderian and D. Melody (2006), 'Do we need a world health insurance to realise the right to health?', PLoS Medicine, 3(12): e530.

Öhler, H., P. Nunnenkamp and A. Dreher (2012), 'Does conditionality work? A test for an innovative US aid scheme', European Economic Review, 56: 138-153.

Paul, E. (2015), 'Performance-based aid: why it will probably not meet its promises', Development Policy Review, 33(3): 313-323.

Paul, E. and F. Vandeninden (2012), 'Foreign aid transaction costs: what are they and when are they minimised?', Development Policy Review, 30(3): 283-304.

Pearson, L. B., E. Boyle, R. de Oliveira Campos, C. D. Dillon, W. Guth, W. A. Lewis, R. E. Marjolin and S. Okita (1969), Partners in Development: Report of the Commision on International Development, London: Pall Mall Press.

Perakis, R. and W. Savedoff (2015), 'Does results-based aid change anything? Pecuniary interests, attention, accountability and discretion in four case studies', CGD Policy Paper 052, Center for Global Development, Washington, DC.

Reddy, S. and A. Heuty (2004), 'Achieving the MDGs: A critique and a strategy', Harvard Center for Population and Development Studies Working Paper Series 14 (3).

Resch, S., T. Ryckman and R. Hecht (2015), 'Funding AIDS programmes in the era of shared responsibility: an analysis of domestic spending in 12 low-income and middle-income countries', Lancet Global Health, 3: e52-e61.

Salvado, R. C. and J. Walz (2013), 'Aid eligibility and income per capita: a sudden stop for MICs?', DPAF Working Paper Series, Seattle: Bill \& Melinda Gates Foundation.

Silverman, R. L., M. Over and S. Bauhoff (2015), Aligning Incentives, Accelerating Impact: Next Generation Financing Models for Global Health Report for the Center for Global Development Working Group on Next Generation Financing Models in Global Health Washington, DC: Center for Global Development.

Sumner, A. (2012), 'Where do the poor live?', World Development, 40(5): 865-877.

Sumner, A. (2016), 'The world's two new middles. Growth, precarity, structural change, and the limitations of the special case', WIDER Working Paper 2016/34, Helsinki: United Nations University World Institute for Development Economics Research.

Svensson, J. (2000), 'When is foreign aid policy credible? Aid dependence and conditionality', Journal of Development Economics, 61: 61-84.

Taskforce on Innovative International Financing for Health Systems (HLTF) (2009), 'More money for health, and more health for the money'. Taskforce on Innovative International Financing for Health Systems, http://www.internationalhealthpartnership.net/fileadmin/ uploads/ihp/Documents/Results__Evidence/HAE_results_lessons/Taskforce_report_EN.2009. pdf [28 June 2015]. 
Temple, J. R. W. (2010), 'Aid and conditionality', in D. Rodrik and M. Rosenzweig eds Handbook of Development Economics Volume 5 Amsterdam: North-Holland, 4415-4523.

United Nations General Assembly (UNGA) (2012), 'Scale of assessments for the apportionment of the expenses of the United Nations'. United Nations General Assembly Resolution 67/238, Sixty-Seventh Session.

Verbeke, K. and R. Renard (2011), 'Development cooperation with middle-income countries', IOB Working Paper, Antwerpen: Institute of Development Policy and Management, University of Antwerp.

World Bank (2015), 'World Bank GNI per capita operational guidelines \& analytical classifications', http://siteresources.worldbank.org/DATASTATISTICS/Resources/OGHIST.xls [28 June 2015].

World Health Organisation (WHO) (2015), World Health Statistics 2015, Geneva: World Health Organization. 